\title{
CETI: put not your trust in beacons
}

D. R. Bates, of the Department of Applied Mathematics and Theoretical Physics, Queen's University, Belfast, argues that it would be unjustified to devote resources to the interstellar communication problem on the assumption that there is a neighbouring technological civilisation which continuously operates a beacon signal suited to us.

THOSE active in promoting interstellar communication, for example through the $\$ 10,000$ million Project Cyclops, have faith that a neighbouring technologically advanced civilisation, $\mathbf{X}$, would continuously operate a suitable beacon signal that, in addition to showing our civilisation (a technological novice) the star to which to send the acknowledgement signal, would carry other information. Most favour the beacon being omnidirectional because such a beacon by embracing all possible respondents within range, would avoid the contact-time difficulty.

People are heedless to the needs of their descendants as their exploitation of the Earth's resources demonstrates. No terrestrial government would support a costly beacon if it were advised that a response (of debatable benefit) would be unlikely to be received for 200 years. In the case of a government on $\mathrm{X}$, I shall quixotically suppose that the corresponding period is normally 1,000 years. This millennium criterion is a key factor. It would be imprudent for us to incur expenditure on the assumption that $\mathrm{X}$, if indeed it exists, has a succession of governments with a multi-millennium criterion or with a sustained resolve to pass knowledge to alien species on distant planets.

On the millennium criterion the government of $X$ would only finance a beacon if the probable distance to the closest potential respondent were expected to be less than 500 light years. From the spatial distribution of stars it follows that the number of potential respondents in the Galaxy would have to exceed the critical number

$$
N_{\mathrm{c}} \simeq 5 \times 10^{4}
$$

Drake's equation gives

$$
N=R L
$$

$N$ being the equilibrium number of technological civilisations in the galaxy, $R$ their annual rate of emergence and $L$ their mean lifetime in years. The widely quoted estimate for $R, 0.1$ per

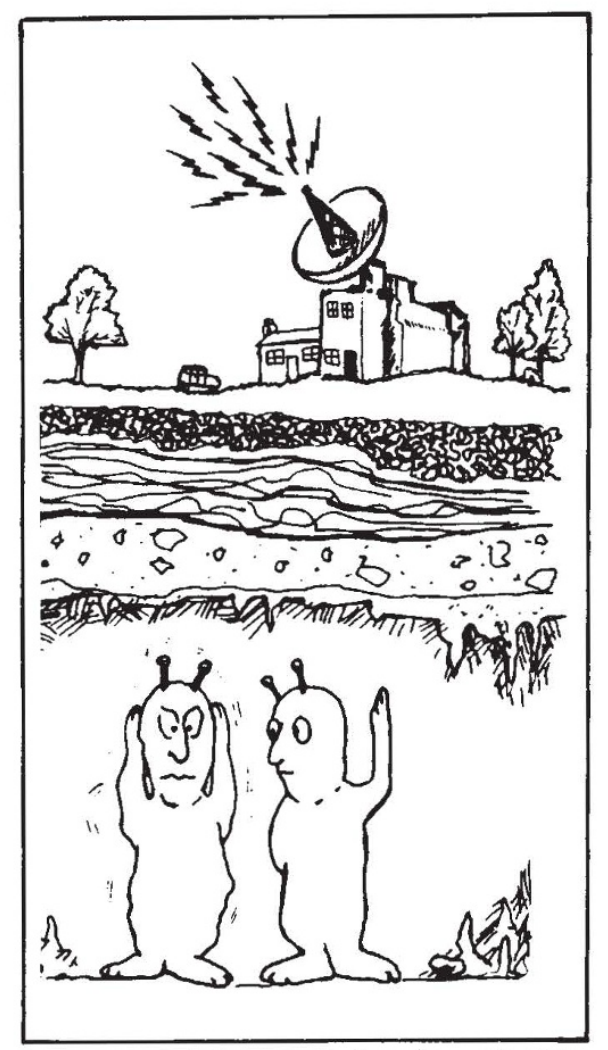

year, cannot be much too low. It may well be much too high: thus it rests on the dubious assumption that the abundant $\mathrm{M}$ and $\mathrm{K}$-type stars are amongst the hosts and on the dogmatic assumption that the unknown probability of life developing on an apparently suitable planet is unity. Young technological civilisations (up to several times as old as us with age measured from the release of nuclear energy) are clearly so few comvared with $N_{\mathrm{c}}$ that they would be dismissed as potential respondents on the millennium criterion.

Some may survive adolescent dangers and conceivably have lifetimes on the stellar evolutionary scale. Perhaps a sufficient fraction do so to make $L$ long enough (at least millions of years) for $N_{\mathrm{c}}$ to be exceeded. Even granted this, a doubt remains. Ancient civilisations would have explored virtually all of science; they would have sophisticated historical records and rich cultural heritages to study. Many may lose interest in possible signals and even in astronomy, leaving the number in the communicative phase less than required.

Suppose that $\mathrm{X}$ has hitherto been isolated. Doubtless signal detection has been thoroughly tried: it has the attraction that its initiators might themselves have the satisfaction of witnessing success. Scientists of $\mathrm{X}$ could only guess the probable distance to the closest potential respondent. Some might ask a government to finance a beacon project. For a government to spend unnecessarily on the basis of a guess would be strange. My quixotic supposition is that it does so provided the project satisfies the millennium criterion. In addition to the costs of constructing the beacon and associated power station the costs of maintaining and replacing them arise. Thought would therefore be given to the length of time for which transmission would be justified.

The number of advanced civilisations within the range of the beacon fluctuates around its equilibrium value. Such civilisations emerge at the annual rate

$$
R_{\mathrm{B}}=R / N_{\mathrm{C}} \simeq 2 \times 10^{-5} R
$$

which is very slow. Hence the chance of getting a response would not be significantly increased by signalling for the full millennium rather than just for several decades. Several decades would suffice for the beacon to be noticed by any interested advanced civilisation within range and for much information to be carried by its signal (though whether or not this would reach another civilisation would be a dispiritingly open question).

If no replies came by the end of the millennium scientists on $X$ would conclude that no potential respondents were within range. To increase the beacon's range ten-fold would necessitate increasing its power a hundredfold. Scientists wishing this might attempt to find support for signalling efforts which at best might be acknowledged between 1,000 and 10,000 years later. We would be prodigal to divert resources from promising research on the assumption that they would succeed.

If replies to the first beacon came, the triumph would not make it much easier to persuade a government of $\mathrm{X}$ to finance a second. A better case could be made for financing a brief beacon project (covering hitherto unexplored stars) by a government of one of the respondents not already in contact with other civilisations.

Should a communication cell once be established, its radius might expand at a speed comparable with that of light until the entire Galaxy were occupied. For this to be possible the total number of civilisations in the communicative phase would have to exceed $N_{C}$, which is large. Because of the slowness of the emergence rate given 
by equation (3), it would be improvident for us to proceed on the assumption that a government of a civilisation belonging to the hypothetical communication network would finance a prolonged beacon project aimed merely at hastening contact with any relatively recently developed oivilisation rather than leaving the initiative to the newcomer as the one having the greater incentive and the easier problem.

The inference that it would be irresponsibly optimistic to assume that civilisations operate beacons for more than minute fractions of their lifetimes in the communicative phase has an important consequence. It follows im- mediately from Drake's equation that relatively few beacons can realistically be expected to co-exist. A proper allocation of research effort cannot ignore that we are hence probably much farther from the nearest beacon than the beacon is from its intended respondents. The acute difficulty this causes is greatly aggravated by another factor.

The communication techniques of a civilisation initially improve rapidly but improvement cannot continue indefinitely. Instead the rate of improvement must decrease and eventually become vanishingly small. Presumably all civilisations which survive long enough reach a common level of technical attainment, and presumably most beacons are designed by and suited to those at or near this common level. A comparison betwen Projests Ozma and Cyclops shows strikingly how rapidly our techniques are still improving. The pattern of our development can scarcely be such that Project Cyclops, though far ahead of Project Ozma, is close behind what may ultimately be achieved. Yet, unless the pattern is indeed such, we must be technically much too backward for it to be wonth our while engaging in the basically extremely formidable task of searching for signals.

\section{international news}

Persistent reports of the arrest, torture and execution of doctors and other health workers have been filtering out of Chile ever since Salvador Allende's government was overthrown by the armed forces last year. Although the military junta has consistently denied such charges, most conspicuously in a full-page advertisement in the New York Times, an investigation by three biomedical scientists with support from the Federation of American Scientists (FAS) has now accumulated considerable evidence that left wing members of the medical profession have indeed been a prime focus for particularly brutal reprisals since the junta seized power.

Most of their findings simply back up many previous allegations of brutality, but the report breaks new ground with its analysis of why doctors in particular were singled out for harsh treatment and it also has some disquieting things to say about the Colegio Medico-me Chilean equivalent of the British Medical Association.

First, the Colegio played an active part in Allende's downfall by organising two damaging strikes, one in 1972 and the second immediately before the coup, and it issued two demands for Allende's resignation. After the armed forces seized power and began rounding up Allende's supporters, however, the Colegio did nothing to defend the rights of any of its members, even though its own code of ethics states that it is obliged to defend accused physicians. As Dr Leonard Sagan of the Palo Alto Medical Clinic, who led the investigation, puts it: "the Colegio took almost a brutal delight in the overthrow (of Allende) but it had no compassion whatsoever for its members who were arrested".

\section{Reprisals against Chilean doctors}

\author{
by Colin Norman, Washington
}

In particular, the report notes that one doctor, Carlos Shuster, wrote a letter to the Rector of the University of Chile suggesting that all physicians be classified into three groups "those above suspicion, those with leftish sympathies and those beyond rehabilitation". That letter "seems to have suggested to authorities a general system for classification of health workers into A, B, and C lists", the report suggests, and those lists later served as a basis for arrests and other reprisals.

Local responsibility for compiling the lists fell to direators of hospitals and chiefs of service, the report states, and "while we were unable to obtain direct evidence, it seems probable that officials of the Colegio Medico, on the national and local levels, were involved in preparing lists of physicians considered not only dangerous but also politically unacceptable". It adds, however, that only in the Medical School of the University of Chile "did we hear, from the dean, a clear distinction between ideological allegiances and participation in violence. The dean asserted that, at least within his jurisdiction, this distinction has been respected."

Appearance on a list had a variety of consequences. "In some cases it appears that certain physicians were marked for death", the report states; others were arrested and several have been barred from working for the health service-which is tantamount to denying them a job at all.

The investigating team says that it has "good evidence" of 176 physicians who have been suspended from the health service, and it has a list of 109 physicians who had been imprisoned up to June this year. Dr Sagan said last week, however, that the figure for total arrests of doctors is probably nearer 300 . In addition, some 250 doctors have fied the country since the coup.

As for reports of executions, the team arrived in Chile with a list of 28 doctors believed to have been shot, but several of the reparts turned out to have been unfounded. They found good evidence, however, that at least fifteen doctors have died since the coup, and "of those deaths for which we have relatively reliable information, death occurred shortly after arrest in the month of September". The most common excuse given by the authorities was that prisoners were shot while trying to escape, but the report states that such a story is implausible at best.

Finally, the report notes that allegations of torture are widespread, but "are difficult or impossible for foreigners to substantiate in a charged political environment". Nevertheless, the investigating team repeatedly heard two disturbing allegations about the source of the methods of torture used. First, a repont that a group of Brazilians were brought to Chile to train the Chilean military was "widely heard" and, second, "there are frequent references to an American training camp in Panama where South American military officers are indoctrinated in techniques of resisting torture, thereby providing technology on the information of torture". 